\title{
Expression of Alpha-actinin-4 in Human Diabetic Nephropathy
}

\author{
Moritsugu Kimura, Masao Toyoda, Mayuko Kato, Keiko Kobayashi, Makiko Abe, \\ Takako Kobayashi, Masaaki Miyauchi, Naoyuki Yamamoto, \\ Tomoya Umezono and Daisuke Suzuki
}

\begin{abstract}
Background Alpha-actinin-4 is an actin filament crosslinking protein that interacts with intercellular adhesion molecules. Recent animal studies suggested that alpha-actinin-4 is an essential component of the glomerular filtration barrier. However, little is known about its expression in human diabetic nephropathy (DN).

Methods Renal biopsy tissues were obtained from 17 patients with DN. We determined the mRNA and protein expression levels of alpha-actinin-4 by in situ hybridization and immunohistochemistry. The histopathological severity of DN was classified into two groups: mild and moderate mesangial expansion groups. We also measured urinary protein excretion and creatinine clearance.

Results Podocytes were positively stained for alpha-actinin-4 mRNA and protein. In the glomeruli, the percentage of cells positive for alpha-actinin- 4 mRNA was significantly lower in moderate mesangial expansion group than in mild mesangial expansion group and control. The percentage of immunohistochemically positive area for alpha-actinin-4 protein in moderate mesangial expansion group was significantly lower than in mild mesangial expansion group and control. The percentage of cells positive for alpha-actinin- 4 mRNA and area positive for the protein correlated inversely with severity of proteinuria.

Conclusion Our results suggest that low expression levels of alpha-actinin-4 mRNA and protein are linked to the progression of glomerulopathy and proteinuria in human DN.
\end{abstract}

Key words: proteinuria, in situ hybridization, immunohistochemistry

(Inter Med 47: 1099-1106, 2008)

(DOI: 10.2169/internalmedicine.47.0352)

\section{Introduction}

Alpha-actinin-4 is an actin-binding cytoskeletal protein and one of four alpha-actinin isoforms in the human body. Both alpha-actinin-2 and -3 are expressed on myocytes, while the expression of alpha-actinin-1 and -4 were identified on cultured mouse podocytes (1). They have also been found to localize near cell adhesion molecules such as integrin and catenin in cells other than myocytes, and seem to play a role in the regulation of cell morphology and motility (2). In addition, alpha-actinins are also considered to play a role in intracellular signaling (3).
The mechanisms leading to the development of proteinuria in renal disease remain obscure in many respects, although various hypotheses have been proposed (4-6). In recent years, the hypothesis that changes in podocyte signaling and the morphological alteration of the podocytes themselves (including the slit membrane) and may be involved in the development of proteinuria has been advanced based on the results of animal model studies (7-9). Kidney disease patients with proteinuria often show morphological alterations in podocytes such as foot process effacement. Thus, for a better understanding of the mechanism underlying the development of proteinuria, it is important to determine the relationship between morphological abnormalities and functional 
abnormalities of podocytes.

As part of our research on changes to the slit membranes of podocytes, recently we examined the expression of nephrin, a protein related to the slit membrane, in patients with diabetic nephropathy (DN) and reported that a decrease in nephrin mRNA expression is closely correlated with the onset or progression of proteinuria in patients with DN (10). In the past few years, several other molecules such as podocin, CD2AP, ZO-1, P-cadherin, were identified to be associated with the slit diaphragm complex, and some of these molecules are critical for its integrity. Based on these recent insights into the molecular pathology of podocytes, many researchers have focused their attention on the understanding of the relationship between slit diaphragm-related proteins, the actin cytoskeleton, and the dynamics of foot process structure in renal diseases. Recently, Kos et al (11) investigated the expression of nephrin and podocin, which are structural proteins of the slit membrane, in mice deficient in alpha-actinin-4, because alpha-actinin-4 is considered to play an important role in the maintenance of podocyte morphology. Based on their findings, they proposed the hypothesis that the development of proteinuria in this mouse model was mainly due to cytoskeletal changes caused by deficiency of alpha-actinin-4 rather than changes in the structural proteins of the slit membrane. However, the alteration of alphaactinin-4's expression in human DN podocytes is still not understood. whether the expression of alpha-actinin-4 in podocytes is altered in human DN tissues is still not understood. The present study was designed to determine the role of alpha-actinin-4 in the development of proteinuria in such patients. Specifically, we investigated alpha-actinin-4 mRNA and protein expression in the kidneys of patients with DN.

\section{Subjects and Methods}

\section{Patients}

Renal biopsy tissues were obtained from 17 patients with DN. We also examined control samples obtained from 5 subjects using uninvolved portions of surgically removed kidneys afflicted with malignancies. The presence of DN was confirmed by histopathological evaluation of renal biopsy specimens using light microscopy, immunofluorescence staining and electron microscopy. After resection, the kidney samples were embedded in optimal cutting temperature (OCT) compound (Tissue Tek; Miles, Elkhart, IN) and stored until use. Severity of DN was classified into two groups based on histopathological examination of periodic acid-Schiff (PAS)-stained renal biopsy specimens as follows. We calculated the percentage of mesangial area relative to the total glomerular area to determine the degree of mesangial expansion in renal tissues. To minimize bias, 5 glomeruli were selected from all glomeruli in each patient and in control samples. The criterion for selection was the crosssection through their vascular poles. We measured the total glomerular area and PAS-positive area using an automatic

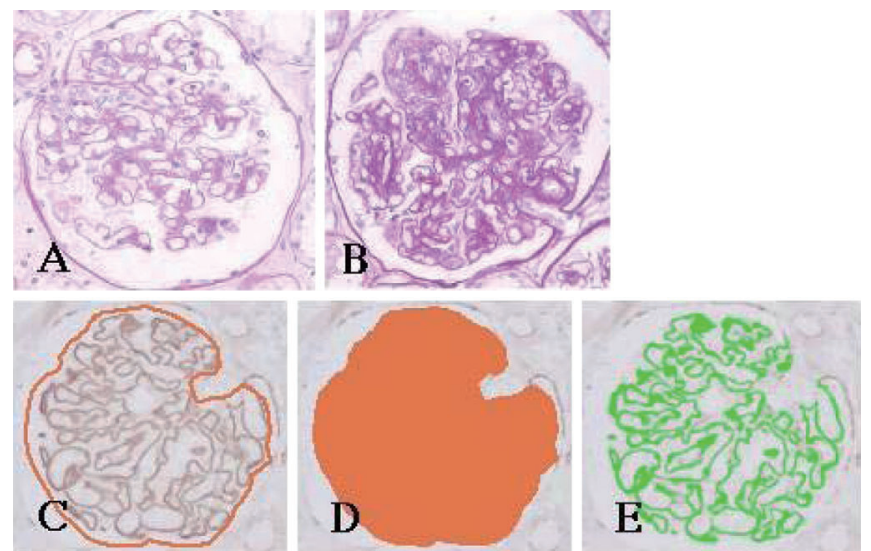

Figure 1. Light microscopic findings in glomeruli from representative patients with DN prepared by periodic acidSchiff staining. Severity of DN was classified based on the degree of mesangial expansion. (A) Mild mesangial expansion group. Note the mild degree of mesangial expansion (original magnification $\times 100)$. (B) Moderate mesangial expansion group. Note the moderate degree of mesangial expansion $(\times 100)$. The expression level of alpha-actinin-4 protein was quantitated by expressing the results as (C) percentage of immunohistochemically-positive area in a glomerulus = $(E) /(D) \times 100$, where (D) is the total area of the glomerulus, and $(E)$ is the immunohistochemically-positive area in the glomerulus.

image analyzer determined by three independent investigators. We then calculated the percentage of mesangial area relative to the total glomerular area (\%Mes). DN was classified into the mild mesangial expansion group $(n=7, \%$ Mes $<$ $20.0 \%)$ and moderate mesangial expansion group $(n=10, \%$ Mes $\geqq 20.0 \%$ ) (Fig. 1).

The Human Research Committee of Tokai University School of Medicine approved the study, and informed consent for renal biopsy and in situ hybridization and immunohistochemistry studies was obtained from each patient prior to the commencement of the study. The following clinical parameters were examined at the time of renal biopsy: gender, age, systolic blood pressure, diastolic blood pressure, serum creatinine, total protein, HbAlc, urinary protein and creatinine clearance (Table 1).

\section{In situ hybridization}

The following nucleotide sequence of human alphaactinin-4 cDNA was used as the probe : CTGGCTGGCGAACTGGCGGCGCAGGTGCTC. Of the oligonucleotide probe, $100 \mathrm{pM}$ was labeled, using a digoxigenin (DIG) oligonucleotide tailing kit according to the standard protocol (Roche Diagnostics GmbH, Penzberg, Germany). The free DIG was removed by ethanol precipitation, and dissolved in diethylpyrocarbonate-treated water. In situ hybridization was performed according to the modified technique developed in our laboratory (12). Briefly, freshly biopsied kidney tissue was embedded in OCT compound and stored at $-70^{\circ} \mathrm{C}$ for future use. Specimens were cut to a 
Table 1. Clinical Parameters at the Time of Renal Biopsy in Patients with Diabetic Nephropathy and Control

\begin{tabular}{|c|c|c|c|c|}
\hline & $\begin{array}{l}\text { Mild mesangial } \\
\text { expansion group } \\
(\mathrm{n}=7)\end{array}$ & $\begin{array}{l}\text { Moderate mesangial } \\
\text { expansion group } \\
(\mathrm{n}=10)\end{array}$ & $\begin{array}{l}\text { Control } \\
(\mathrm{n}=5) \\
\end{array}$ & $\mathrm{p}$-value \\
\hline Gender $\left(M^{\prime} F\right)$ & 611 & $7 / 3$ & 213 & N.D. \\
\hline Age (yr) & $37.7 \pm 10.4^{*}$ & $49.0 \pm 8.5$ & $56.2 \pm 6.0 * *$ & $<0.05$ \\
\hline $\mathrm{SBF}(\mathrm{mmHg})$ & $138.0 \pm 17.0$ & $151.3 \pm 21.9$ & $131.2 \pm 8.3$ & N.S. \\
\hline $\mathrm{DBP}(\mathrm{mmHg})$ & $79.4 \pm 8.9$ & $84.5 \pm 14.9$ & $80.4 \pm 9.0$ & N.S. \\
\hline Serum creatinine (mg'd1) & $0.8 \pm 0.2$ & $1.0 \pm 0.3$ & $0.8 \pm 0.1$ & N.S. \\
\hline Total protein (g/d1) & $6.7 \pm 0.6$ & $5.2 \pm 1.2$ & $6.5 \pm 0.3$ & N.S. \\
\hline HbAlc (\%) & $10.3 \pm 3.3$ & $8.8 \pm 2.7$ & N.D. & N.S. \\
\hline Urinary protein (g/day) & $0.24 \pm 0.34 *$ & $3.20 \pm 2.90^{* * * *}$ & $0.03 \pm 0.02 * *$ & $\leqslant 0.05$ \\
\hline Creatinine clearance $(\mathrm{ml} / \mathrm{min})$ & $101.6 \pm 17.2^{*}$ & $71.6 \pm 20.5$ & $90.5 \pm 3.5$ & $<0.05$ \\
\hline
\end{tabular}

Data are expressed as mean $\pm \mathrm{SD}$.

${ }^{*} \mathrm{p}<0.05$ ws. Moderate mesangial expansion group, ** $p<0.05$ ws. Mild mesangial exparsion group, $* * * p<0.05$ ws. Control, N.D, not done, SBP : systoric blood pressure, DBP : diastoric blood pressure, N.S. not significant.

thickness of $4 \mu \mathrm{m}$, and then fixed in $4 \%$ paraformaldehyde in phosphate-buffered saline. They were then deproteinized with $\mathrm{HCl}$ and digested with proteinase $\mathrm{K}$ (Sigma-Aldrich Co, St. Louis, MO). The specimens were pre-hybridized in a hybridization buffer, drained, and then hybridized overnight with a DIG-labeled oligonucleotide probe in the hybridization buffer. After hybridization, the DIG-labeled probe was visualized by immunohistochemical staining using a mouse monoclonal anti-DIG antibody (Roche Diagnostics, Indianapolis, IN), horseradish peroxidase (HRP)-conjugated rabbit anti-mouse IgG antibody (DakoCytomation Denmark, Glostrup, Denmark), and HRP-conjugated swine anti-rabbit IgG antibody (Dako). Color was developed with diaminobenzidine tetrahydrochloride in $0.05 \mathrm{M}$ Tris- $\mathrm{HCl}, \mathrm{pH} 7.6$, and $0.03 \% \mathrm{H}_{2} \mathrm{O}_{2}$. Sections were briefly counterstained with hematoxylin, rinsed, dehydrated, cleared in xylene and mounted. To avoid the bias of signal intensity, in situ hybridization study was performed at one time and the color development time was also uniform.

To evaluate the specificity of the signals, two types of control experiments were carried out, as described previously (12). First, pre-treatment with RNase (Roche Diagnostics) followed proteinase $\mathrm{K}$ digestion, then each section was pre-hybridized and hybridized. Second, a competitive study was performed by adding a 100-fold excess amount of homologous or unrelated, unlabelled oligonucleotides to the hybridization buffer together with the antisense probe. The expression level of alpha-actinin-4 mRNA was quantitated by counting all nuclei as well as nuclei surrounded by mRNA-positive cytoplasm in at least 5 randomly selected cross-sections of nonsclerotic glomeruli and by expressing the results as a percentage of total cells. The alpha-actinin-4 mRNA expression level was quantitated by three independent investigators who were blind to the histopathological classification of each specimen.

\section{Immunohistochemistry}

After fixation, kidneys were embedded in paraffin. Immunohistochemical staining was performed on $4 \mu \mathrm{m}$ thick sections using the ABC immunoperoxidase method. The antibody (anti-actinin-4 affinity purified rabbit antibody IG701) for alpha-actinin-4 was purchased from immunoGlobe Antikörpertechnik (Himmelstadt, Germany). The Elite ABC kit was purchased from Vector Laboratories (Birmingham, CA). Paraffin sections were deparaffinized and rehydrated. Endogenous peroxidase activity was quenched by incubating the sections in $0.9 \% \mathrm{H}_{2} \mathrm{O}_{2}$ for $3 \mathrm{~min}$. To unmask antigens, slides were boiled at $121^{\circ} \mathrm{C}$ for $10 \mathrm{~min}$ in $0.1 \mathrm{M}$ sodium citrate buffer ( $\mathrm{pH}$ 6.0). Sections were treated overnight with 5\% normal horse serum before incubation with primary antibodies at $4^{\circ} \mathrm{C}$. To avoid the bias of signal intensity, immunohistochemistry method was performed at one time and the color development time was also uniform. Negative controls were treated with 5\% normal horse serum without the primary antibodies. Signals were processed according to the supplied protocol (Elite ABC Kit). The expression level of alpha-actinin-4 protein was also quantitated by expressing the results as percentage of immunohistochemically-positive area in a glomerulus using the image analysis system Win ROOF (Mitani, Fukui, Japan) (Fig. 1). We also performed immunohistochemistry study using Wilms' Tumor 1 (WT-1) antibody as a marker for podocyte. The affinity purified rabbit polyclonal antibody, anti-human WT-1 antibody (C-19) was purchased from Santa Cruz Biotechnology (Santa Cruz, CA, USA).

\section{Confirmation of alpha-actinin-4 down-regulation}

To verify the down-regulation of alpha-actinin-4, we also 


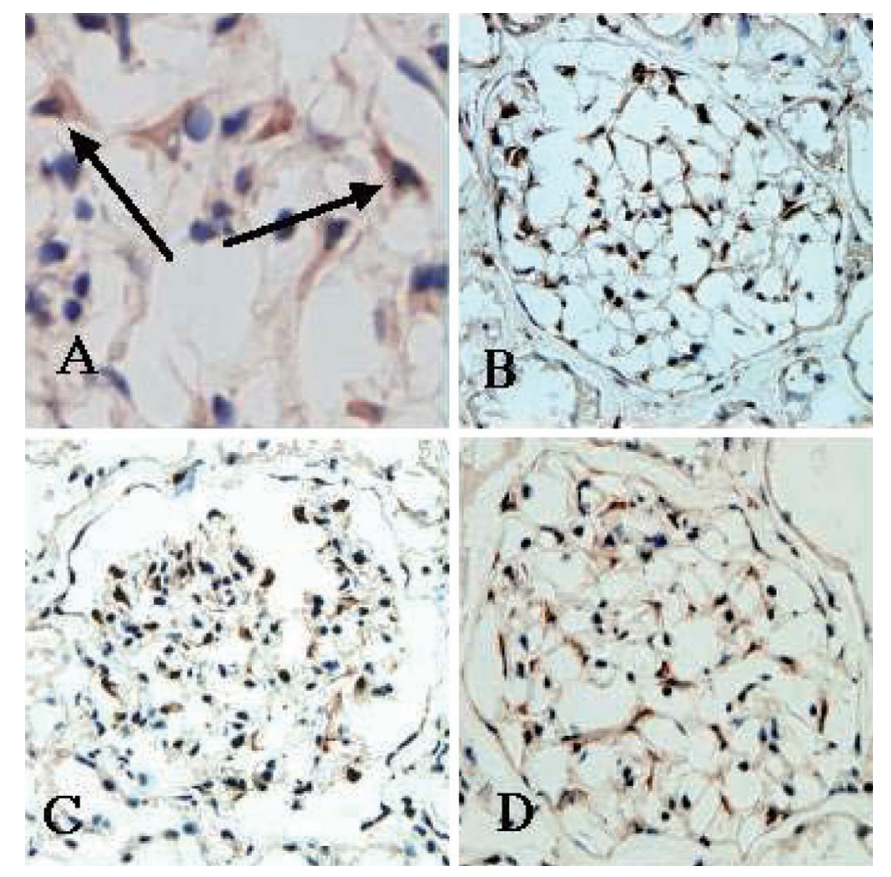

Figure 2. In situ hybridization of alpha-actinin-4 mRNA in glomeruli of renal tissue samples of patients with $\mathrm{DN}$ and control. In situ hybridization revealed exclusive localization of alpha-actinin-4 mRNA in podocytes (arrows) [(A) Mild mesangial expansion group, $\times 200]$. The proportion of glomerular cells positive for alpha-actinin-4 mRNA in moderate mesangial expansion group was less than in mild mesangial expansion group and control. [(B) Mild mesangial expansion group, $\times 100,(\mathrm{C})$ Moderate mesangial expansion group, $\times \mathbf{1 0 0}$, (D) Control, $\times 100]$.

performed in situ hybridization methods using beta-actin mRNA probe as the control gene. The following nucleotide sequence of human beta-actin cDNA was used as the probe: CTGGCTGGCGAACTGGCGGCGCAGGTGCTC. For this confirmation study, 15 renal tissues were studied (mild=5, moderate $=5$ and control $=5$ respectively).

\section{Statistical analysis}

Data are expressed as mean \pm SD. Differences between groups were analyzed for statistical significance by using the Mann-Whitney U-test or Kruskal-Wallis test. The relationships between alpha-actinin-4 mRNA or protein expression and clinical parameters were examined using Spearman rank correlation test and linear regression analysis. A $p$ value of $<0.05$ was considered statistically significant.

\section{Results}

\section{Detection of alpha-actinin-4 mRNA and protein}

Our in situ hybridization method demonstrated cells positive for alpha-actinin-4 mRNA in renal tissues of DN. As shown in Fig. 2, in situ hybridization identified individual cells positive for alpha-actinin-4 mRNA. High-magnification views indicated that these cells were exclusively podocytes

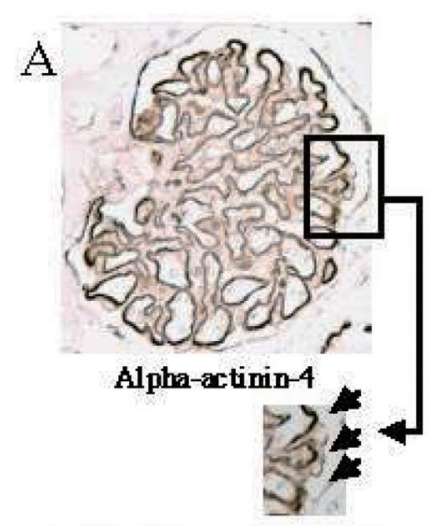

C
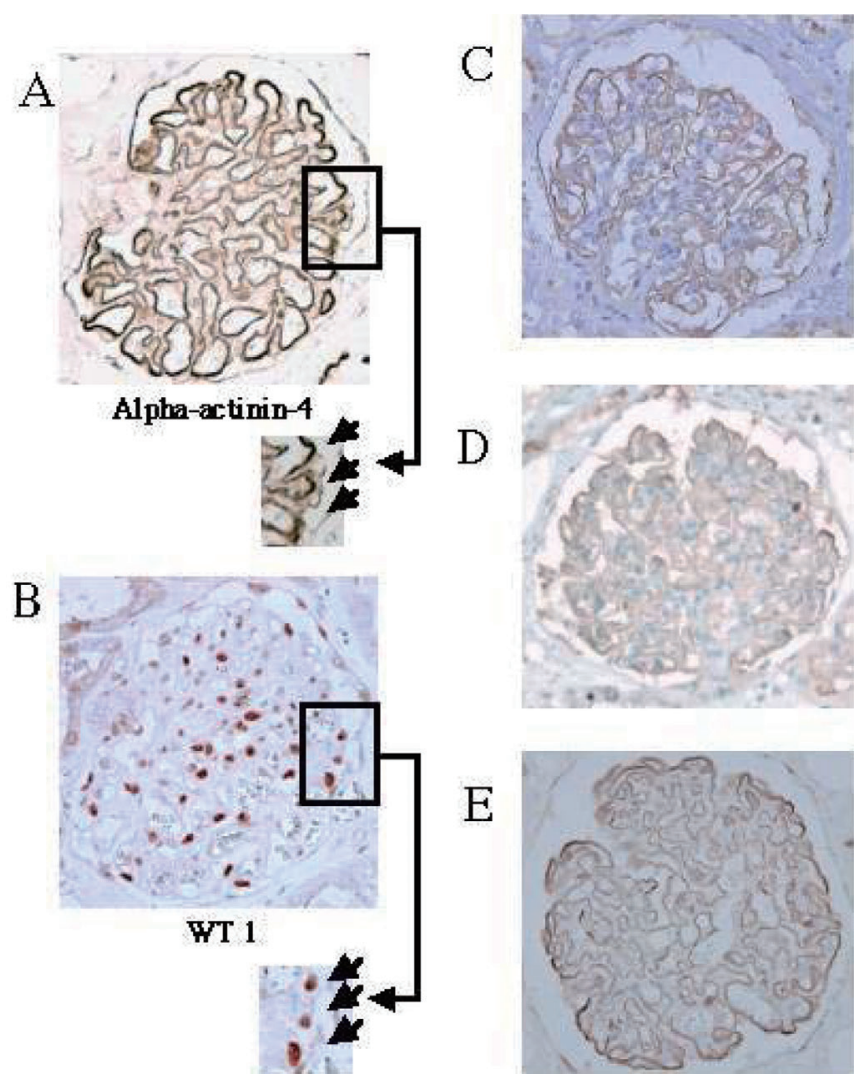

Figure 3. Immunohistchemistry of serial staining for alphaactinin-4 and WT-1 antibody clearly identified individual cells. These WT-1 positive cells (Fig. 3B) are in the same areas of alpha-actinin-4 positive protein (arrows) (Fig. 3A). [(A) Control, $\times 100, \times 200,(B)$ Control, $\times 100, \times 200]$. Detection of alpha-actinin-4 protein in representative tissues of $\mathrm{DN}$ and control. [(C) mild mesangial expansion group, $\times 100$, (D) Moderate mesangial expansion group, $\times 100$, (E) Control $\times 100]$. The immunohistochemically-positive alpha-actinin- 4 protein in moderate mesangial expansion group was less than in mild mesangial expansion group and control.

(Fig. 2A). As shown in Fig. 2B-2D the number of glomerular cells positive for alpha-actinin-4 mRNA in moderate mesangial expansion group (Fig. 2C) was lower than in mild mesangial expansion group (Fig. 2B) and control (Fig. 2D). Figure 3 shows examples of positive immunohistochemical signals for alpha-actinin-4 protein in the three groups and serial staining for alpha-actinin-4 and WT-1 antibody in controls. As shown in Fig. 3A and 3B, serial staining for alphaactinin-4 and WT-1 antibody clearly identified individual cells. These WT-1 positive cells (Fig. 3B) also expressed alpha-actinin-4 protein (Fig. 3A). These results revealed that alpha-actinin-4 positive signals were exclusively detected in podocytes in a linear pattern and the positive area for alphaactinin-4 protein in moderate mesangial expansion group (Fig. 3D) was lower than in mild mesangial expansion group (Fig. 3C) and control (Fig. 3E) (Table 2).

\section{Analysis of mRNA and protein expression levels}

The results of quantitative analysis of alpha-actinin-4 
Table 2. Comparison of Alpha-Actin-4 mRNA and Protein Experssion in Patients with Diabetic Nephropathy and Control

\begin{tabular}{lllll} 
& $\begin{array}{l}\text { Mild mesangial } \\
\text { expansion group } \\
(\mathrm{n}=7)\end{array}$ & $\begin{array}{l}\text { Moderate mesangial } \\
\text { expansion group } \\
(\mathrm{n}=10)\end{array}$ & $\begin{array}{c}\text { Control } \\
(\mathrm{n}=5)\end{array}$ & p-value \\
\hline & & & & \\
$\begin{array}{l}\text { Alpha-actinin-4 } \\
\text { mRNA (\%) }\end{array}$ & $18.3 \pm 4.2$ & $7.9 \pm 5.2^{*}$ & $22.4 \pm 4.1$ & 0.05 \\
$\begin{array}{l}\text { Alpha-actinin-4 } \\
\text { protein }(\%)\end{array}$ & $16.5 \pm 6.5$ & $7.79^{*}$ & $20.6 \pm 1.6$ & $\infty .05$ \\
\hline
\end{tabular}

$$
{ }^{*} p<0.05 \text { ws. mild mesangial expansion group and control. Data are expressed as mean } \pm \mathrm{SD} \text {. }
$$

Table 3. Comparison of Alpha-Actin-4 and Beta-actim mRNA Experssion in Patients with Diabetic Nephropathy and Control

$\begin{array}{llll}\text { Mild mesangial } & \text { Moderate mesangial } & \text { Control } & \text { P-value } \\ \text { expansion group } & \begin{array}{l}\text { expansion group } \\ (n=5)\end{array} & (n=5) & \end{array}$

\begin{tabular}{|c|c|c|c|c|}
\hline $\begin{array}{l}\text { Alpha-actinin-4 } \\
\text { mRNA (\%) }\end{array}$ & $15.4 \pm 1.8$ & $9.7 \pm 1.7^{*}$ & $19.1 \pm 5.7$ & $<0.05$ \\
\hline $\begin{array}{l}\text { Beta-actin } \\
\text { mRNA (\%) }\end{array}$ & $20.3 \pm 3.9$ & $18.0 \pm 3.3$ & $25.5 \pm 8.2$ & N.S. \\
\hline
\end{tabular}

* p<0.05 w. mild mesangial expansion group and control. $\quad$ Data are expressed as mean \pm SD.

N.S., not significant.

mRNA and protein are summarized in Table 2. In the glomeruli, the percentage of cells positive for alpha-actinin4 mRNA in moderate mesangial expansion group was significantly lower than mild mesangial expansion group and control. Furthermore, the percentage of immunohistochemically positive area for alpha-actinin-4 protein in moderate mesangial expansion group was also significantly lower than in mild mesangial expansion group and control. In situ hybridization study using beta-actin mRNA probe revealed the down regulation of alpha-actinin-4 compare with beta-actin (Table 3).

Further analysis showed inverse correlations between the percentage of cells positive for alpha-actinin- 4 mRNA, the percentage of immunohistochemically positive area for alpha-actinin-4 protein and the severity of proteinuria (Fig. 4A and B). There was a positive correlation between the expression level of alpha-actinin-4 mRNA and creatinine clearance (Fig. 4C), while there was no correlation between the expression level of alpha-actinin-4 protein and creatinine clearance (Fig. 4D). There were also inverse correlations between the percentage of cells positive for alpha-actinin-4 mRNA, the percentage of immunohistochemically positive area for alpha-actinin-4 protein and severity of glomerular mesangial expansion (Fig. 4E and F).

Discussion

The pathogenesis of proteinuria in patients with progressive renal disease is considered to be partly related to loss of the barrier to serum proteins that normally exists in the glomerular capillary wall, which is comprised of capillary endothelial cells, glomerular basement membrane, and podocytes (13). A recent study in an animal model of focal and segmental glomerulosclerosis (FSGS) reported the relationship between alterations of alpha-actinin-4 expression and the pathogenesis of proteinuria, as well as between reduced nephrin expression and proteinuria (14). Furthermore, it has been reported that mutations of alpha-actinin- 4 are associated with morphological changes in podocytes, such as foot process effacement, as well as thickening of the basement membrane and the development of proteinuria (14). Thus, there is evidence based on animal models that alterations of alpha-actinin-4 expression in podocytes seem to play a role in the pathogenesis of proteinuria. In this regard, Gassler et al reported that damage of podocytes could lead to tuft adhesion of glomeruli, resulting in global glomerulosclerosis of DN (15).

Taking this viewpoint, it is conceivable that the patho- 

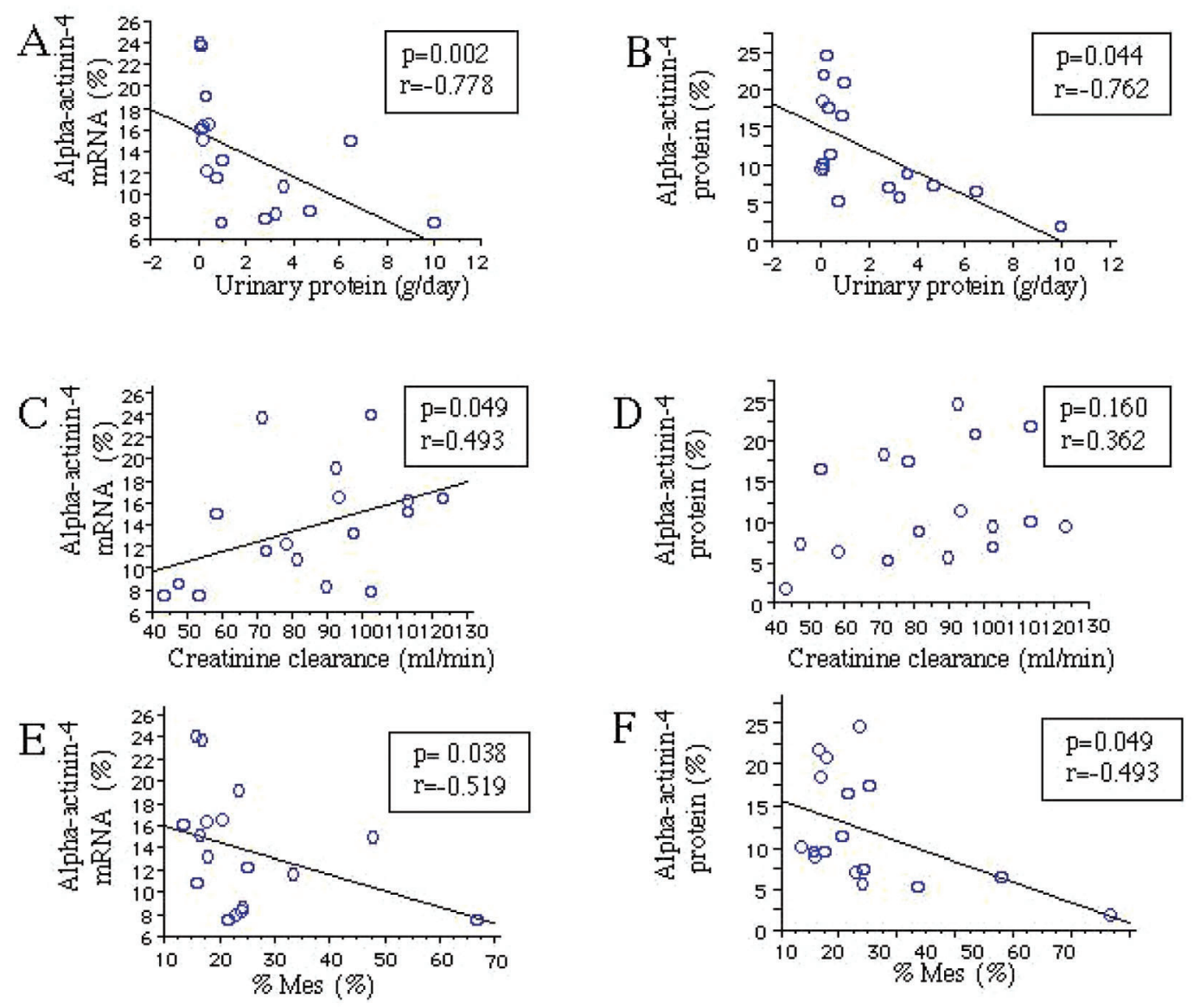

Figure 4. Correlation between alpha-actinin-4 expression and severity of proteinuria. [(A) mRNA vs.urinary protein, (B) protein vs. urinary protein]. Correlation between alpha-actinin-4 expression and creatinine clearance. [(C) mRNA vs. creatinine clearance, (D) protein vs. creatinine clearance]. Correlation between alpha-actinin-4 expression and severity of glomerular mesangial expansion (\% Mes.). [(E) mRNA vs. \% Mes., (F) protein vs. \% Mes.].

genesis of DN includes, at least in part, changes related to podocyte damage. However, there is little or no information at present regarding alpha-actinin-4 expression in kidney tissues of patients with DN.

Other podocyte proteins expression, which related to the slit membrane were also studied in renal tissues of patients with DN or diabetic animal models. Kelly et al reported that the reduction in nephrin might be a determinant of glomerular hyperpermeability in diabetic animal model (16). We also previously reported that nephrin might play an important role in the development and progression of proteinuria in DN (10). Benigni et al reported that reduction of nephrin in the context of normal expression of CD2AP and podocin could be taken reasonably as a specific marker of renal disease in diabetes (17). Other recent report about ZO-1, which expressed at the junction of podocytes with the slit diaphragm, revealed alterations in the content and localization of ZO-1 may be relevant to the pathogenesis of proteinuria in DN (18). These reports indicate that the proteinuria was caused by alteration in the structural proteins of the podocyte. Meanwhile, Kos et al proposed the hypothesis that the development of proteinuria in their mouse model was mainly due to cytoskeletal changes caused by deficiency of alpha-actinin-4 rather than changes in the structural proteins of the slit membrane (11). From this point, it is interesting to examine the expression of alpha-actinin-4, which is an actin-binding cytoskeletal protein, in renal tissues of patients with DN.

In the present study, we examined alpha-actinin- 4 expression in the glomerulus, using kidney specimens from patients with DN. We demonstrated at both mRNA and protein levels (by in situ hybridization and immunohistochemistry) that alpha-actinin-4 were exclusively expressed on podocytes. Interestingly, renal samples from patients with moderate mesangial expansion group (who showed greater proteinuria and more advanced glomerular changes than those with mild mesangial expansion group and the control) exhibited reduced alpha-actinin-4 expression for both mRNA and protein. The percentage of cells positive for alpha-actinin-4 mRNA and area positive for the protein were correlated inversely with glomerular mesangial expansion (\%Mes). These results suggest that down-regulation of alpha-actinin-4 may relate to severity of DN. Furthermore, in these diabetic groups the percentage of cells positive for alpha-actinin-4 mRNA and area positive for the protein correlated inversely with 24-hour urinary protein excretion. There are two possi- 
bilities that would explain these findings. The first is that the reduced protein expression of alpha-actinin- 4 could be involved in both the onset and, we may verify the down regulation of alpha-actinin-4 mRNA expression in DN. The other possibility is that loss of podocytes occurs in DN and this could lead to reduced expression of alpha-actinin-4 because it is exclusively expressed by podocytes in glomeruli progression of proteinuria in DN patients, as well as in the morphological changes of podocytes. In this study, we performed in situ hybridization methods using beta-actin mRNA probe. From our results, it is difficult to state if the reduced alpha-actinin-4 mRNA expression in moderate mesangial expansion group is only due to down-regulation of alpha-actinin- 4 by the diabetic state or is also due to the loss of podocytes.

Based on recent results on the molecular pathology of podocytes, several major pathomechanisms of proteinuria have been considered: 1) abnormalities of the slit diaphragm complex; 2) abnormal interactions between podocytes and the basement membrane; 3) changes in alpha-actinin-4, and 4) changes in molecules bearing a negative charge on the podocytes (19-26). The results of the present study suggest that the reduced alpha-actinin- 4 mRNA and protein expression levels could cause damage to podocytes and result in the development of proteinuria. However, the precise mechanisms of the regulation of alpha-actinin-4 expression on podocytes are still not fully understood. Therefore, there is a need to investigate the regulatory mechanisms that control alpha-actinin-4 expression under both normal and pathological conditions, especially in diabetic conditions.

In this study, we did not examine the other podocyterelated proteins such as nephrin and podocin. Recent study using the urinary sediment of patients with DN suggested that there might be a difference between nephrin expression and alpha-actinin-4 expression (27). Therefore, further studies of other podocyte-related proteins are needed in human renal tissues with DN.

In conclusion, we used human renal tissue samples from patients with DN to determine alpha-actinin-4 mRNA and protein expression by DIG-labeled in situ hybridization and immunohistochemistry. Our results suggest that low expression of both mRNA and protein of alpha-actinin-4 are closely linked to the progression of glomerular lesion and proteinuria in human DN.

\section{References}

1. Welsch T, Endlich N, Kriz W, Endlich K. CD2AP and p130Cas localize to different F-actin structures in podocytes. Am J Physiol Renal Physiol 281: F769-777, 2001.

2. Honda K, Yamada T, Endo R, et al. Actinin-4. A novel actinbinding protein associated with cell mortality and cancer invasion. J Cell Biol 140: 1383-1393, 1998.

3. Burgueno J, Blake DJ, Benson MA, et al. The adenosine A2A receptor interacts with the actin-binding protein alpha-actinin. J Biol Chem 278: 37545-37552, 2003.

4. Noakes PG, Miner JH, Gautam M, Cunningham JM, Sanes JR, Merlie JP. The renal glomerulus of mice lacking s-laminin/laminin beta 2: nephrosis despite molecular compensation by laminin beta 1. Nat Genet 10: 400-406, 1995.

5. Hamano Y, Grunkemeyer JA, Sudhakar A, et al. Determinants of vascular permeability in the kidney glomerulus. J Biol Chem 277: 31154-31162, 2002.

6. Yang JC, Haworth L, Sherry RM, et al. A randomized trial of bevacizumab, an anti-vascular endothelial growth factor antibody, for metastatic renal cancer. N Engl J Med 349: 427-434, 2003.

7. Liu G, Kaw B, Kurfis J, Rahmanuddin S, Kanwar YS, Chugh SS. Neph1 and nephrin interaction in the slit diaphragm is an important determinant of glomerular permeability. J Clin Invest 112: 209-221, 2003.

8. Aaltonen $\mathrm{P}$, Luimula $\mathrm{P}$, Astrom E, et al. Changes in the expression of nephrin gene and protein in experimental diabetic nephropathy. Lab Invest 81: 1185-1190, 2001.

9. Li C, Ruotsalainen V, Tryggvason K, Shaw AS, Miner JH. CD2 $\mathrm{AP}$ is expressed with nephrin in developing podocytes and is found widely in mature kidney and elsewhere. Am J Physiol Renal Physiol 279: F785-792, 2000.

10. Toyoda M, Suzuki D, Umezono T, et al. Expression of human nephrin mRNA in diabetic nephropathy. Neprol Dial Transplant 19: 380-385, 2004.

11. Kos $\mathrm{CH}$, Le TC, Sinha $\mathrm{S}$, et al. Mice deficient in alpha-actinin-4 have severe glomerular disease. J Clin Invest 111: 1683-1690, 2003.
12. Suzuki D, Miyazaki M, Naka R, et al. In situ hybridization of interleukin 6 in diabetic nephropathy. Diabetes 44: 1233-1238, 1995.

13. Levidiotis V, Power DA. New insights into the molecular biology of the glomerular filtration barrier and associated disease. Nephrology (Carlton) 10: 157-166, 2005.

14. Michaud JL, Lemieux LI, Dube M, Vanderhyden BC, Robertson SJ, Kennedy CR. Focal and segmental glomerulosclerosis in mice with podocyte-specific expression of mutant alpha-actinin-4. J Am Soc Nephrol 14: 1200-1211, 2003.

15. Gassler N, Elger M, Kranzlin B, et al. Podocyte injury underlies the progression of focal segmental glomerulosclerosis in the fa/fa Zucker rat. Kidney Int 60: 106-116, 2001.

16. Kelly DJ, Aaltonen P, Cox AJ, et al. Expression of the slitdiaphragm protein, nephrin, in experimental diabetic nephropathy: differing effects of anti-proteinuric therapies. Nephrol Dial Transplant 17: 1327-1332, 2002.

17. Benigni A, Gagliardini E, Tomasoni S, et al. Selective impairment of gene expression and assembly of nephrin in human diabetic nephropathy. Kidney Int 65: 2193-2200, 2004.

18. Rincon-Choles H, Vasylyeva TL, Pergola PE, et al. ZO-1 Expression and phosphorylation in diabetic nephropathy. Diabetes 55: 894-900, 2006.

19. Pagtalunan ME, Miller PL, Jumping-Eagle $S$, et al. Podocyte loss and progressive glomerular injury in type II diabetes. J Clin Invest 99: 342-348, 1997.

20. Liu XL, Kilpelainen P, Hellman U, et al. Characterization of the interactions of the nephrin intracellular domain. FASEB J 272: 228-243, 2005.

21. Regele HM, Fillipovic E, Langer B, et al. Glomerular expression of dystroglycans is reduced in minimal change nephrosis but not in focal segmental glomerulosclerosis. J Am Soc Nephrol 11: 403412, 2000.

22. Orlando RA, Takeda T, Zak B, et al. The glomerular epithelial cell anti-adhesin podocalyxin associates with the actin cytoskeleton through interactions with ezrin. J Am Soc Nephrol 12: 1589- 
1598, 2001

23. Takeda T, McQuistan T, Orlando RA, Farquhar MG. Loss of glomerular foot processes is associated with uncoupling of podocalyxin from the actin cytoskeleton. J Clin Invest 108: 289-301, 2001.

24. Smoyer WE, Mundel P, Gupta A, Welsh MJ. Podocyte alphaactinin induction precedes foot process effacement in experimental nephrotic syndrome. Am J Physiol 273: F150-157, 1997.

25. Kaplan JM, Kim SH, North KN, et al. Mutations in ACTN4, en- coding alpha-actinin-4, cause familial focal segmental glomerulosclerosis. Nature Genet 24: 251-256, 2000.

26. Kretzler M, Teixeira VP, Unschuld PG, et al. Integrin-linked kinase as a candidate downstream effector in proteinuria. FASEB $\mathrm{J}$ 15: 1843-1845, 2001.

27. Wang G, Lai FM, Lai KB, et al. Messenger RNA expression of podocyte associated molecules in the urinary sediment of patients with diabetic nephropathy. Nephron Clin Pract 106: c169-c179, 2007.

(C) 2008 The Japanese Society of Internal Medicine http://www.naika.or.jp/imindex.html 